\title{
LA APROPIACIÓN DEL LÉXICO ETTE TAARA EN EL CICLO MOOMATE DE LA INSTITUCIÓN ETNOEDUCATIVA DEPARTAMENTAL ETTE ENNAKA
}

\author{
Sindy Paola Narváez Escobar \\ Universidad del Atlántico (Colombia) \\ spnarvaez@mail.uniatlantico.edu.co
}

Recibido: 15/02/2020 - Aprobado: 26/05/2020

DOI: doi.org/10.17533/udea.lyl.n78a14

\begin{abstract}
Resumen: Esta investigación tuvo como objetivo fortalecer los procesos de apropiación del léxico ette taara (familia lingüística) en estudiantes del ciclo Moomate (preescolar) de la Institución Etnoeducativa Departamental del Resguardo Issa Oristunna, en Sabanas de San Ángel (Magdalena, Colombia). A través de un trabajo de campo, se recolectaron los datos mediante observación participante, encuestas, entrevistas, procesos dialógicos y grabación del léxico. Se concluyó que los etnoeducadores entienden la necesidad de que sus estudiantes se apropien de su lengua materna, pero carecen de materiales didácticos fundamentales para su enseñanza. Esto derivó en la creación de una aplicación móvil como herramienta de aprendizaje.
\end{abstract}

Palabras clave: etnoeducación; estratégia didáctica; lexicografía ette taara; aplicación; ette ennaka.

\section{THE APPROPRIATION OF THE ETTE TAARA LEXICON IN THE MOOMATE CYCLE OF THE DEPARTAMENTAL ETHNOEDUCATIONAL SCHOOL ETTE ENNAKA}

\begin{abstract}
This research aimed to strengthen the processes of appropriation of the ette taara lexicon (linguistic family) in students of the Moomate cycle (preschool) of the Departmental Ethno-Educational Institution of the Issa Oristunna Reservation, in Sabanas de San Ángel (Magdalena, Colombia). Through fieldwork, data was collected through participant observation, surveys, interviews, dialogic processes and lexicon recording. It was concluded that ethno-educators understand the need for their students to appropriate their mother tongue, but lack essential teaching materials. This led to the creation of a mobile application as a learning tool.
\end{abstract}

Key words: ethnoeducation; didactic strategy; Ette Taara lexicography; application; Ette Ennaka. 


\section{Introducción}

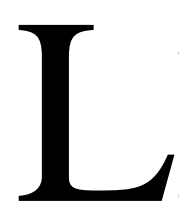

a comunidad ette ennaka ${ }^{1}$, cuyos miembros son también llamados chimilas (Bolinder, 1987; Reichel-Dolmatoff, 1946; Uribe, 1987), ha implementado acciones en los últimos años para la revitalización del ette taara ${ }^{2}$ como lengua materna, en especial, aquellas que garanticen a las nuevas generaciones su enseñanza y aprendizaje. En el modelo etnoeducativo de los ette ennaka se establece que los niños deben apropiarse del uso pragmático tanto de su lengua materna, el ette taara, como de su segunda lengua, el español. Todo ello centrado en un proceso de inmersión contextual, con lo cual se espera que al final de la escolarización alcancen:

[...] la comprensión plena de lo que se escucha y la expresión eficiente de lo que se piensa; de la misma manera para el lenguaje escrito: comprensión plena de lo que se lee y expresión eficiente a partir de la escritura, de lo que se piensa (Trillos et al., 2014).

La importancia de enfocarse en las nuevas generaciones para la revitalización de la lengua se soporta en los resultados de varias investigaciones, de las cuales se resalta el informe preliminar de la primera campaña de autodiagnóstico sociolingüístico 2008-2010. del Ministerio de Cultura (MinCultura, 2010), cuyo objetivo es identificar para cada grupo étnico la situación actual de vitalidad lingüística, manifestada en la cantidad de hablantes, el uso, la transmisión y la valoración que hacen los integrantes de los grupos étnicos de sus lenguas nativas. En este informe se determina que el ette taara es una lengua que se ubica en la categoría de severo peligro, ya que, sus hablantes fluentes son una minoría y donde las nuevas generaciones casi no hablan la lengua nativa.

Otro aspecto que contribuyó al desplazamiento de la lengua fue el hecho de sufrir la pérdida total de su territorio por procesos de colonización en la región, donde según Trillos (1996, p. 14) una vez diezmados y como una forma de preservación de la integridad física, los chimilas comenzaron a negar su identidad y con ello la lengua.

Teniendo en cuenta lo anterior, la investigación buscó coadyuvar a la comunidad indígena en vivificar su lengua materna: la ette taara. Por lo que se trazó como objetivo

1. ette ennaka «Propia gente».

2. ette taara «El habla de la gente». 
general fortalecer la apropiación del léxico ette taara en los niños del ciclo Moomate de la IEDEE $^{3}$. Seguidamente se elaboró un diagnóstico sobre los procesos didácticos que se desarrollan con los niños del ciclo Moomate de la IEDEE. Luego, se recolectó un corpus del léxico ette taara en uso de los niños del ciclo Moomate. Asimismo, se identificó experiencias significativas en la enseñanza de la lengua.

La investigación se sustentó en los planteamientos de Higueras (2009), Allen (1983), López et al., (2016), Tébar (2003), Constenla (1993), Cárdenas et al., (2013), Meza (2015), entre otros autores. Además, se tuvieron como referentes las investigaciones realizadas en torno al ette taara y su enseñanza (Trillos Amaya et al., 2014; Niño, 2018).

\section{Generalidades}

\subsection{Ubicación geográfica de la comunidad ette ennaka}

El pueblo ette ennaka se encuentra ubicado en el departamento del Magdalena. Esta cuenta legalmente ${ }^{4}$ con cuatro resguardos. El primero se llama, Issa Oristunna (en español, tierra de la nueva esperanza), ubicado en el municipio de Sabanas de San Ángel, departamento del Magdalena; donde se encuentra la mayor concentración de miembros. El segundo, se denomina Ette Butteriya (en español, pensamiento propio), situado en el mismo municipio, a 20 kilómetros de Issa Oristunna. Tanto Issa Oristunna como Ette Butteriya están constituidos por varias fincas adquiridas por el Incora $^{5}$ y Corpamag $^{6}$, entregadas a la comunidad en calidad de resguardo.

3. IEDEE (Institución Etnoeducativa Departamental Ette Ennaka): Ubicada en el resguardo indígena Issa Oristunna, en el municipio de Sabanas de San Ángel, departamento del Magdalena, fue adoptada en 1990 por solicitud propia a la Congregación Misioneras de la Madre Laura. Esta institución, pertenece al sector oficial y sigue los lineamientos del Proyecto Etnoeducativo Comunitario (PEC). La entidad alberga a estudiantes de preescolar, básica primaria, básica secundaria y media, en las jornadas matutina, fin de semana y jornada única. El modelo etnoeducativo de los ette ennaka se caracteriza por ciclos de aprendizaje y rutas etnoeducativas para adecuar la realidad educativa a la cultura y tradición ette ennaka, la cual incluye los ciclos: Moomate, Kogramuиna, Kogramaana y Jasasakreya.

4. El 19 de noviembre de 1990, el Incora (seccional del Departamento del Magdalena) expidió la resolución 075 , por medio de la cual se constituyó el primer resguardo.

5. Instituto Colombiano de la Reforma Agraria.

6. Corporación Autónoma Regional del Magdalena. 
En tercera instancia, Narakajmantas (en español, nuestra Madre Tierra), es una finca ubicada en zona rural de Santa Marta, vereda El Mosquito, corregimiento de Gaira, a orillas del río Gaira y sobre estribaciones noroccidentales de la Sierra Nevada de Santa Marta. Por último, Itti Takke (en español, Nueva Tierra), recientemente considerado como resguardo mediante la Resolución del 5 de diciembre de 2013, se encuentra ubicado en la vereda Miraflores del corregimiento de Chimila, en el municipio de El Copey, departamento del Cesar. Por su parte, Diwana (en español, Sol Naciente), se ubica entre los municipios de Valledupar y Chimichagua, en el departamento del Cesar, sobre las estribaciones del sur de la Sierra Nevada de Santa Marta.

Según el Plan de Salvaguarda (2012), además de los asentamientos mencionados, existen familias disgregadas por los caseríos y veredas aledañas que cubren la sabana entre el río Magdalena y el río Ariguaní. En otros casos habitan en las zonas urbanas de algunos municipios, como Chimichagua, Valledupar, Santa Marta y Ariguaní. En el proceso de construcción del Plan de Salvaguarda, las comunidades periféricas reconocidas como las más numerosas fueron María Angola (de la comunidad Diwana), ubicada entre Valledupar y Chimichagua, departamento del Cesar; Barro Blanco, municipio de Santa Bárbara de Pinto y San Pedro. Otros lugares donde se encontraron familias del pueblo ette ennaka son: Bosconia, Aguas Blancas y Becerril (departamento del Cesar); Santa Marta, Las Mulas, Chivolo, Pivijay, Ariguaní, El Difícil, Céspedes, Monterrubio y Santa Ana, (departamento del Magdalena); Maicao, Monguí y Puente Quemado (departamento de La Guajira); y por último, en los municipios de Magangué y Granada, (departamentos de Bolívar y Sucre, respectivamente). 


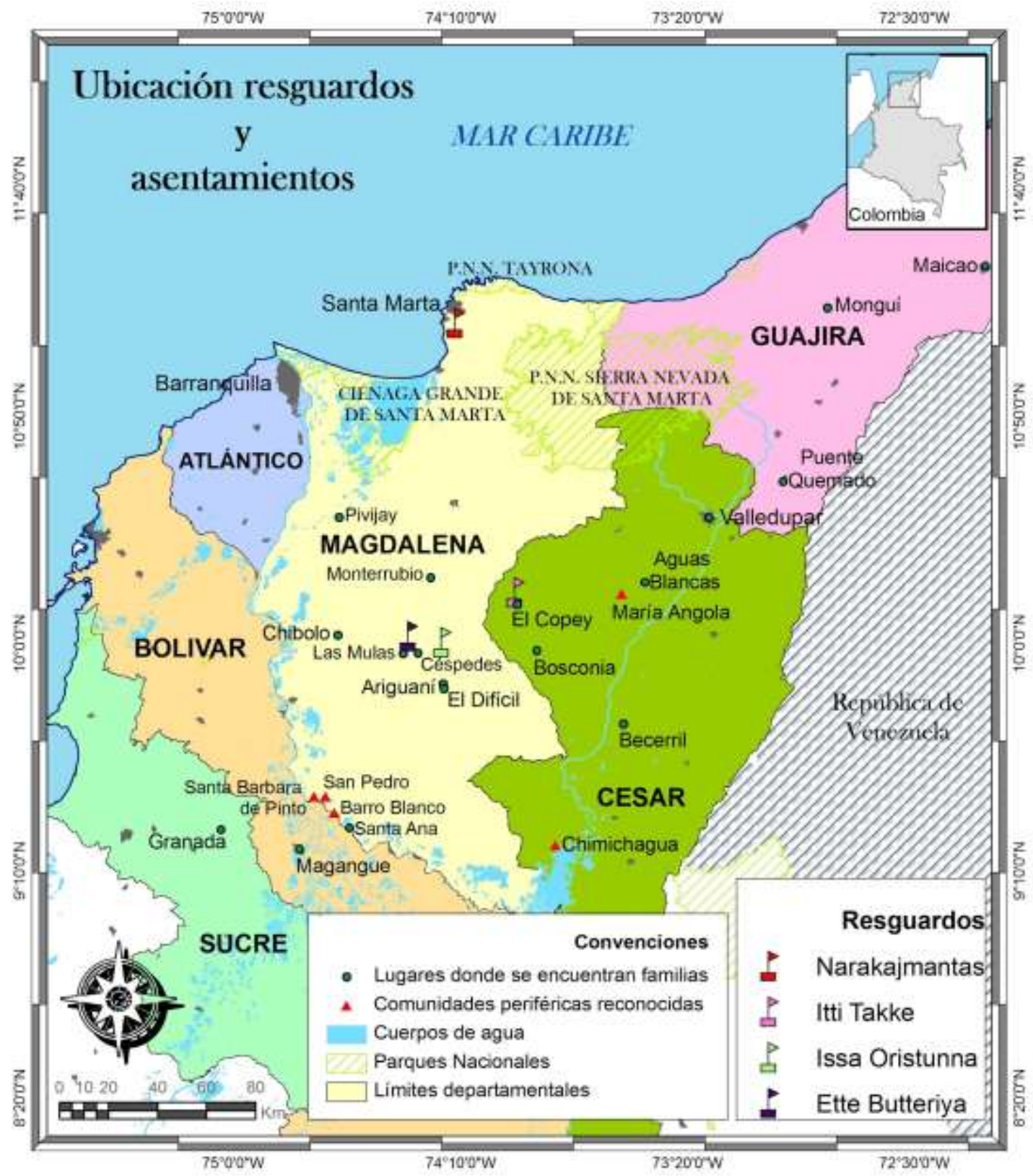

Figura 1. Actuales resguardos y asentamientos de los ette ennaka. Mapa elaborado por Ríos (2019).

\subsection{Caracterización de la lengua ette taara}


El ette taara es la lengua propia de los ette ennaka. Durante mucho tiempo fue una lengua de tradición oral, no tenía escritura. Fue transmitiendo por siglos de generación en generación, a pesar de las prohibiciones que en diferentes momentos de la historia impusieron los waachas ${ }^{7}$ Sobre el origen del ette taara han surgido diversas teorías acerca de su filiación lingüística. En los estudios realizados por Reichel-Dolmatoff (1946) se planteó que los indígenas chimila asentados en el valle del río Ariguaní pertenecen a la familia arawak. No obstante, el investigador se fundamentó en elementos de la cultura material y no en el estudio de las características lingüísticas del ette taara para realizar esta clasificación. Asimismo, Loukotka (1968, citado por Trillos, 1996) planteó que el ette taara pertenece al grupo malibú de la familia chibcha, pero al lado de lenguas ya desaparecidas como el malibú, mokaná, pacabuy y el papale, el chimila sería la única lengua sobreviviente de este grupo.

De igual forma, los comparatistas han considerado siempre el ette taara como cercano a las lenguas de la Sierra Nevada de Santa Marta (damana, kankuamo, ika y kogui) y a las del altiplano cundiboyacense (muisca, duit). Según investigaciones efectuadas por el profesor Adolfo Constenla (1993), especialista en lenguas chibchas, la lengua del pueblo chimila, pudiera estar coordinada con la familia chibcha en el micrófilo payachibcha. Ello establecería una relación del barí, el cuna, el uwa, las lenguas de la sierra y las del altiplano cundiboyacense con lenguas de Centroamérica, más concretamente Panamá (dorasque, chánguena, entre otras) y Costa Rica (cabécar, bribri, etc.).

Asimismo, de acuerdo con Trillos (1993) existen características semejantes entre las lenguas de la Sierra y el ette taara, bien en su estructura fonológica como en la gramatical (elementos léxicos, sistema de auxiliares, sufijos aspectuales, entre otros). Contrario a esto, se perciben rasgos que nada tendrían que ver con estas lenguas (ascensos y descensos tonales, la cantidad vocálica, los verbos modales y características especiales en la negación). Según la investigadora, esto ratifica la necesidad de realizar estudios más profundos.

En la actualidad, el ette taara cuenta con un reducido número de hablantes, por lo que fue declarada desde el Programa de Protección a las Lenguas Nativas del Ministerio de Cultura de Colombia en estado de precariedad. Apoyados por organizaciones externas, los indígenas

7. wachas: «persona no indígena». 
hoy día cuentan con una forma de escritura creada por trabajos lingüísticos. Están tratando de apropiarse de un alfabeto para que su escritura eventualmente contribuya a salvaguardar este sistema lingüístico. Según Niño (2018), la lengua ette taara ha sido transcrita valiéndose de diferentes tipos de notaciones. En la mayoría de los casos se trata de sistemas fonéticos desarrollados en el marco de estudios académicos. Sin embargo, cabe destacar que en los últimos años en compañía de indígenas de la comunidad e investigadores, se ha podido desarrollar un alfabeto útil para las investigaciones científicas y la producción de textos literarios.

Además, Niño (2018), añadió que en los recientes esfuerzos académicos sobre la descripción de la lengua, investigadores e indígenas intentan diseñar un alfabeto para el registro de material léxico, la enseñanza del idioma en aulas de clases y la redacción de textos. La propuesta más sólida para el diseño del alfabeto fue ideada por el Instituto Lingüístico de Verano - ILV, a través de talleres desarrollados con los indígenas. Buscaban establecer parámetros lingüísticos e iniciar un proceso de escritura de la lengua. Para ello, la institución creó un alfabeto provisional del ette taara, que está compuesto por veinticuatro letras basadas en los símbolos de los cuales se sirve el alfabeto latino y con valores similares a los empleados en la escritura del español. 


\begin{tabular}{|c|c|c|c|}
\hline & \multirow[t]{2}{*}{ Fonema } & \multicolumn{2}{|c|}{ Grafema } \\
\hline & & Minúscula & Mayúscula \\
\hline \multirow{5}{*}{ Vocales } & a & a & A \\
\hline & $\mathrm{e}$ & e & $\mathrm{E}$ \\
\hline & $\mathrm{i}$ & $\mathrm{i}$ & I \\
\hline & o & o & $\mathrm{O}$ \\
\hline & $\mathrm{u}$ & $\mathrm{u}$ & $\mathrm{U}$ \\
\hline \multirow{18}{*}{ Consonantes } & $\mathrm{mb}_{\mathrm{b}}$ & $\mathrm{b}$ & B \\
\hline & ${ }^{\mathrm{n}} \mathrm{d}$ & $\mathrm{d}$ & $\mathrm{D}$ \\
\hline & ts & $\mathrm{ch}$ & $\mathrm{CH}$ \\
\hline & ng & $\mathrm{g}$ & G \\
\hline & 1) & $\mathrm{g}$ & G \\
\hline & $\mathrm{h}$ & $\mathrm{j}$ & $\mathrm{J}$ \\
\hline & $\mathrm{k}$ & $\mathrm{k}$ & $\mathrm{K}$ \\
\hline & 1 & 1 & $\mathrm{~L}$ \\
\hline & $\mathrm{m}$ & $\mathrm{m}$ & $\mathrm{M}$ \\
\hline & $\mathrm{n}$ & $\mathrm{n}$ & $\mathrm{N}$ \\
\hline & $\mathrm{n}_{\mathrm{j}}$ & ny & NY \\
\hline & $\mathrm{n}$ & $\tilde{\mathrm{n}}$ & $\tilde{\mathrm{N}}$ \\
\hline & $\mathrm{p}$ & $\mathrm{p}$ & $\mathrm{P}$ \\
\hline & r & $\mathrm{r}$ & $\mathrm{R}$ \\
\hline & $\mathrm{s}$ & $\mathrm{s}$ & $\mathrm{S}$ \\
\hline & $\mathrm{t}$ & $\mathrm{t}$ & $\mathrm{T}$ \\
\hline & $\mathrm{w}$ & $\mathrm{w}$ & W \\
\hline & $\dot{j}$ & $\mathrm{y}$ & $\mathrm{Y}$ \\
\hline
\end{tabular}

Tabla 1. Alfabeto provisional ette taara. Fuente: Instituto Lingüístico de Verano - ILV.

\section{Marco teórico}

Para el desarrollo del marco teórico y su estructura se tuvo en cuenta como antecedentes algunos estudios y autores del ámbito mundial, que refuerzan el cómo las TIC pueden convertirse en herramienta para el aprendizaje de una lengua. En cuanto a teorías de adquisición del lenguaje se refiere, este estudio se centró en la teoría de Bruner (1984), quien caracterizó las etapas del proceso del habla. A continuación, se presentan algunos aspectos conceptuales de este trabajo etnolingüístico donde se definen los términos categóricos empleados en esta investigación, que se enriquece con cerca de 30 autores y pensamientos afines que respaldan este estudio. 


\subsection{Léxico}

Higueras (2009, citado por Ayala, 2017) manifestó que las unidades léxicas pueden estar constituidas de una o más unidades, esto es, cuando solo una unidad compone la unidad léxica en su totalidad, se puede hablar de una palabra. La apropiación del léxico a través de la enseñanza propone que las unidades léxicas se direccionen a la competencia comunicativa del individuo. En este sentido, el vocabulario asume el rol de un elemento estructurador del pensamiento. Según Allen (1983), este elemento estructurador se conoce como función simbólica y su finalidad se centra en la interacción social o función comunicativa: conocer el léxico de una palabra representa una significación mental que integra funciones cognitivas del lenguaje. Al respecto, Ogden y Richards (1954), plantean que el lenguaje es un medio para conseguir objetivos y para simbolizar relaciones.

\subsection{Componente léxico-semántico}

Según Acosta y Moreno (1999) consideraron que el componente léxico-semántico estudia el significado de las palabras, es decir, el significado que estas ofrecen como unidad y como combinaciones de unidades mínimas. Además, estudia el vínculo que existe entre un significado con otro y las modificaciones que experimenta cada palabra. No obstante, para Clemente (1999), las palabras que son usadas diariamente representan las ideas y concepciones que se tienen acerca de la realidad y no la realidad en sí misma. La realidad está determinada por factores que componen e intervienen en los aspectos semánticos del lenguaje, entre ellos, el entorno educativo, el nivel sociocultural y económico, el sexo y la edad.

Por su parte, Carrasco (2015) concluyó que los niños en edad preescolar se apropian del léxico al incrementar su vocabulario y precisar el alcance y significados de las palabras. Paulatinamente, van obteniendo un conocimiento abstracto del significado, independientemente del contexto e interpretaciones personales. Asimismo, Carrasco (2015), consideró que el niño, después de su primer año y hasta la edad de seis años, incorpora aproximadamente cinco palabras diarias a su vocabulario; es decir, durante este periodo el 
niño evoluciona significativamente apropiándose del léxico y desarrollando habilidades para interiorizar conceptos.

Por tal motivo, es fundamental trabajar en esta etapa estrategias didácticas que faciliten al niño descifrar el significado de las palabras y, en este sentido, se apropien significativamente de un nuevo vocabulario. De este modo, el rol del etnoeducador consiste en comprender cómo el niño aprende a conocer y descubrir el mundo dándole significado a su léxico.

\subsection{Didáctica}

Es la capacidad de enseñar y facilitar el aprendizaje desde el uso de nuevas prácticas y experiencias motivadoras. López. et al., (2016) afirmó que la didáctica vendría a ser la acción del maestro para sostener el objeto de enseñanza poniéndolo a la vista del estudiante, con la intención de que este se apropie de lo que se muestra. En este sentido, las competencias y saberes pedagógicos son quienes determinan las acciones de enseñanza. Por su parte, Medina (2005) resaltó la importancia de una didáctica innovadora que trascienda del emisor al receptor. Para Picado (2006), la didáctica se convierte en ciencia en cuanto se investiga, se experimenta y se crean teorías sobre cómo enseñar, cómo el docente debe «actuar en la enseñanza» con el fin de que el estudiante alcance determinadas metas. En síntesis, la didáctica se entiende como un área del saber que no solo nos dice lo que se debe hacer (el cómo), sino también por qué hacerlo de determinada manera.

\subsubsection{Estrategias didácticas}

Las estrategias didácticas permiten organizar a través de la planeación el proceso de enseñanza. Está direccionado por acciones, objetivos, actividades y recursos que satisfacen los objetivos de aprendizaje. Una adecuada estrategia didáctica fortalece la apropiación del léxico en los estudiantes del ciclo Moomate. En ese sentido, Beltrán y Mansilla (2013) definieron la estrategia didáctica como la estructura de actividades en la que se materializan los objetivos y contenidos de aprendizaje. Para Tébar (2003), la estrategia didáctica es el 
procedimiento que el agente de enseñanza utiliza en forma reflexiva y flexible para promover el logro de aprendizajes significativos en los estudiantes. Para Cárdenas (2013), las estrategias didácticas se caracterizan por estar dirigidas al logro de un objetivo o problema, apoyar el aprendizaje y estimular la personalidad cognitiva a través de procesos de planificación y reflexión en torno a la enseñanza.

De acuerdo con Anzures (2015), las estrategias de aprendizaje son actividades o procesos mentales que llevan a cabo los estudiantes intencionalmente para procesar, entender y adoptar la información que reciben en el proceso educativo. En este sentido, cada actividad, recurso e insumo utilizado responde a las necesidades de cada población, es decir, las estrategias didácticas no pueden estar desarticuladas del contexto que rodea al aprendiz.

\subsubsection{Material didáctico}

En este aspecto, Guerrero (2009) planteó que los materiales didácticos son los elementos que emplean los docentes para facilitar y conducir el aprendizaje del alumno, tales como libros, carteles, mapas, fotos, láminas, videos, software. Así, el material didáctico es considerado como un conjunto de recursos y dispositivos que ayudan a presentar y desarrollar los contenidos y actividades de un curso, es decir, el material didáctico es cualquier elemento presente en un contexto educativo y desarrollado durante una actividad formativa.

\subsection{Experiencias significativas}

Para el Ministerio de Educación Nacional - MEN una experiencia significativa es una práctica concreta (programa, proyecto o actividad) que nace en un ámbito educativo, con el fin, de desarrollar un aprendizaje significativo a través del fomento de las competencias. Se caracteriza por ser innovadora y por atender a una necesidad del contexto que se identificó previamente. La experiencia significativa tiene una fundamentación teórica, metodológica y coherente, generando un impacto saludable en la calidad de vida de la comunidad en la que está inmersa, posibilitando el mejoramiento continuo del establecimiento educativo en 
alguno o en todos sus componentes, tales como el académico, el directivo, el administrativo y el comunitario, fortaleciendo así la calidad educativa.

\section{Metodología}

La metodología se fundamenta en elementos etnográficos que, con base en los planteamientos de Martínez (2011), se encarga de estudiar descriptivamente fenómenos sociales que hacen parte de determinado grupo, comunidad o cultura. La investigación etnográfica supone una práctica reflexiva con el fin de interpretar el contexto sociocultural que le rodea. Según Hernández, Fernández y Baptista (2010) dicho proceso se realiza por medio de instrumentos como la observación, herramientas de anotaciones, diarios de campo, entrevistas, grupos focales, historias de vida, obtención de documentos, entre otros.

Para Murillo (2010), la etnografía educativa trata temas que pueden ser subjetivos en la investigación cuantitativa, por lo que implica tratar los datos de una forma objetiva y descriptiva. En este orden de ideas, el investigador se apoyó en el modelo cuantitativo para abordar el análisis estadístico presente en la investigación. En este sentido, Meza (2015) propuso que el sujeto de la investigación cuantitativa es un ser capaz de despojarse de sus sentimientos, emociones y subjetividad. Hernández, Fernández y Baptista (2010) coincidieron en que «el enfoque cuantitativo utiliza la lógica o razonamiento deductivo» (p. 19). En este sentido, la presente investigación se planteó con un enfoque mixto, ya que este permite integrar en un mismo estudio metodologías cuantitativas y cualitativas con el propósito de que exista mayor comprensión acerca del objeto de estudio (Creswell \& Plano Clark, 2011).

Al respecto, Bavaresco (2013) sostuvo que «la investigación no tiene significado sin las técnicas de recolección de datos. Estas técnicas conducen a la verificación del problema planteado» (p. 95), por lo que la investigación incorporó un sondeo descriptivo compuesto por tres entrevistas: En la primera, de 11 preguntas, se buscó identificar las experiencias didácticas más significativas de los etnoeducadores en la enseñanza del ette taara; luego, la segunda entrevista, con la misma cantidad de preguntas que la primera, se centró en identificar los procesos didácticos que implementaron los docentes del ciclo Moomate en la 
enseñanza del ette taara; y la tercera, con 15 preguntas, se dirigió a los padres de familia, la cual buscó determinar la influencia del núcleo familiar en el proceso de enseñanza de la lengua materna.

Seguidamente, se implementó un sondeo estadístico a través de una encuesta conformada por 24 preguntas. El cuestionario se implementó a estudiantes del ciclo Moomate, con el fin de medir las actitudes y percepciones que los niños tienen frente a su lengua nativa. En este proceso de investigación fue fundamental la participación colectiva de docentes, estudiantes y padres de familia pertenecientes al ciclo Moomate, líderes del pueblo ette ennaka y de los directivos institucionales.

Para la investigación, la población objeto de estudio estuvo conformado por 607 estudiantes pertenecientes a la IEDEE, a partir de la cual se tomó la muestra de carácter intencional, ya que, según Otzen y Manterola (2017) permite seleccionar casos característicos de una población utilizando escenarios en las que la población es muy variable y, por consiguiente, muy reducida. Por lo tanto, la muestra estuvo comprendida por 92 participantes: 48 estudiantes, en edad de 5 a 6 años, 48 padres de familia y 2 docentes, todos pertenecientes al ciclo moomate de la IEDEE, pues es en este grado escolar donde se da inicio al fortalecimiento y apropiación de la lengua vernácula.

\section{Análisis y resultados}

\subsection{Experiencias exitosas utilizadas por los docentes}

Para reconocer las experiencias exitosas en el proceso de enseñanza, fortalecimiento y apropiación del léxico ette taara utilizadas por los etnoeducadores del ciclo Moomate de la institución, se realizó una entrevista a los docentes pertenecientes a este grado de escolaridad, donde se identificaron como experiencias exitosas las siguientes:

a) Uso de elementos sagrados que están vinculados con la naturaleza: a través de historias o dibujos, se enseña a distinguir los animales en ette taara, bien sean domésticos o salvajes, con el fin de que reconozcan su peligrosidad o su condición sagrada. Esta experiencia es así descrita, en palabras del etnoeducador ette ennaka n. ${ }^{\circ} 1$ : 
Nosotros tenemos como esa visión ancestral, que nosotros le colocamos a ellos algo que sea significativo para el pueblo. Entonces, por ejemplo, le dibujamos un pájaro, ese pájaro no se dibuja porque sí, sino por algo, que en la tradición de nosotros ese pájaro es sagrado. Hay animales que son peligrosos, animales que ellos tienen que diferenciar, animales domésticos y animales sagrados que viven en las montañas y que son peligrosos que no se pueden, digamos acercar a ellos, porque corren un riesgo; entonces ya ellos van ahí con esa visión que ven un animal de esos y tienen que tener cuidado, y lo tienen porque por ejemplo hay muchas culebras y ellos la ven y corren avisar que hay una culebra, ellos se abren y ellos saben que ese animal es peligroso. Entonces esas son las experiencias que nosotros como indígenas le damos a ellos y las van captando más rápido.

b) Enseñanza de objetos por asociación. Según el testimonio del etnoeducador ette ennaka n. ${ }^{\circ}$ :

Nosotros cuando enseñamos, por ejemplo, los colores, les traemos un dibujo del color por ejemplo el rojo y vamos pintando objetos que sean de color rojo, una manzana, un corazón, una camisa de color rojo, y así los niños les gusta mucho porque ellos pueden decir otras cosas de ese color y todos van aprendiendo.

c) Demostraciones de bailes tradicionales del pueblo ette ennaka dentro del aula de clase en compañía de sabedoras (mujeres). De acuerdo con el etnoeducador ette ennaka n. ${ }^{02}$ :

Se les enseña el baile tradicional. Entonces se invita a las mujeres sabedoras y ellos van aprendiendo ya desde el preescolar.

d) El uso de materiales del entorno para rellenar objetos o figuras, contar o realizar manualidades. Este proceso se da, en palabras del etnoeducador ette ennaka n. ${ }^{\circ} 1$ :

Trabajamos con materiales del entorno que están ahí disponibles. Si es de salir un ratico con ellos a recogerlos se recogen, se traen y ellos siguen trabajando en el salón con estos, porque muchas veces en matemáticas uno les dice vamos a recoger 10 piedritas chiquitas. Bueno ellos salen, traen su piedrita y los vamos ubicando. Así se les facilita contar los números y los asocian con la cantidad.

e) El aprendizaje por medio de la observación del entorno y de la naturaleza. Según el etnoeducador ette ennaka n. ${ }^{\circ}$, la actividad se lleva cabo así:

Un ratico salimos, los caminamos y los entramos nuevamente y después les decimos qué vieron y entonces ven afuera que les llamó la atención. 
En este sentido, para los etnoeducadores las experiencias de aprendizaje significativo se centran en fomentar y estimular al niño en el aprendizaje de la lengua materna (ette taara) por medio de la cultura y su entorno. Asimismo, se evidencia el propósito de mejorar su rendimiento y eficacia en el funcionamiento de sus capacidades cognitivas, como la memoria, la atención, la percepción y la motricidad. En este orden de ideas, el ambiente familiar, escolar y social supone el principal estímulo para la apropiación del ette taara; aunque el español es el idioma que parlan con mayor facilidad.

\subsection{Actitudes y percepciones de los niños sobre el ette taara como lengua materna dentro del ámbito escolar}

Bajo la orientación del método etnográfico, el cual busca estudiar descriptivamente fenómenos sociales que hacen parte de determinado grupo, comunidad o cultura, se realizó una encuesta con el propósito de identificar las actitudes y percepciones de los escolares objeto de estudio frente a su lengua materna. Para el análisis de los datos, se escogieron como categorías deductivas: 1) Identidad; 2) Actitud hacia la lengua y su enseñanza y 3) Vitalidad lingüística. A partir de esta encuesta se hallaron los siguientes resultados:

\subsubsection{Identidad}

En esta categoría, se analizó qué tan identificados se sentían los niños frente a su etnia. Los estudiantes respondieron positivamente a los interrogantes, reafirmando su orgullo por su pertenencia al pueblo ette taara, reconociendo además que hacen parte de una comunidad indígena, independientemente de si son puros o mestizos. (ver Gráfico 1): 


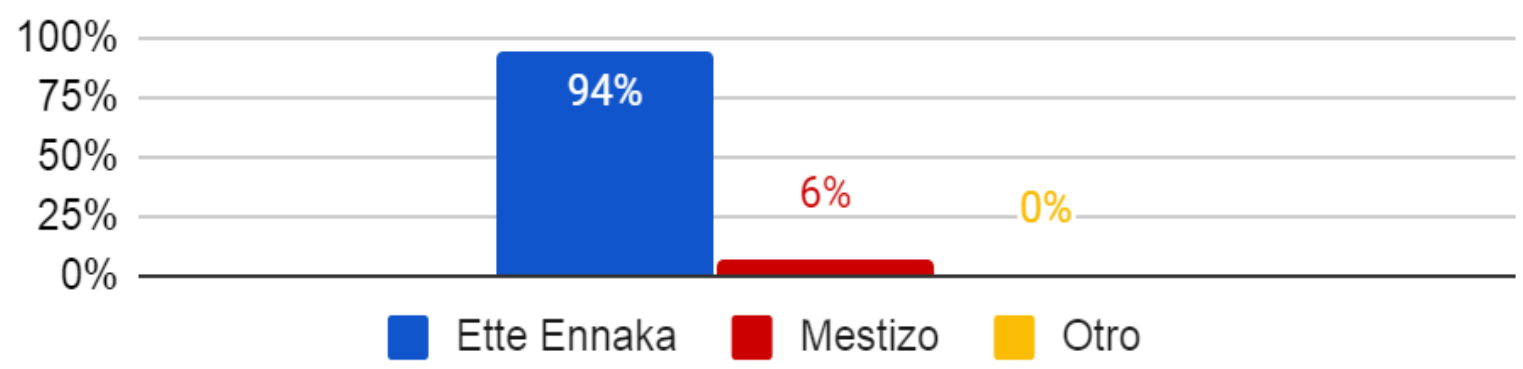

Gráfico 1. Actitudes de los niños ette taara frente a su identidad étnica

Asimismo, los escolares del ciclo moomate reconocen que su núcleo familia igualmente hace parte de una comunidad étnica.

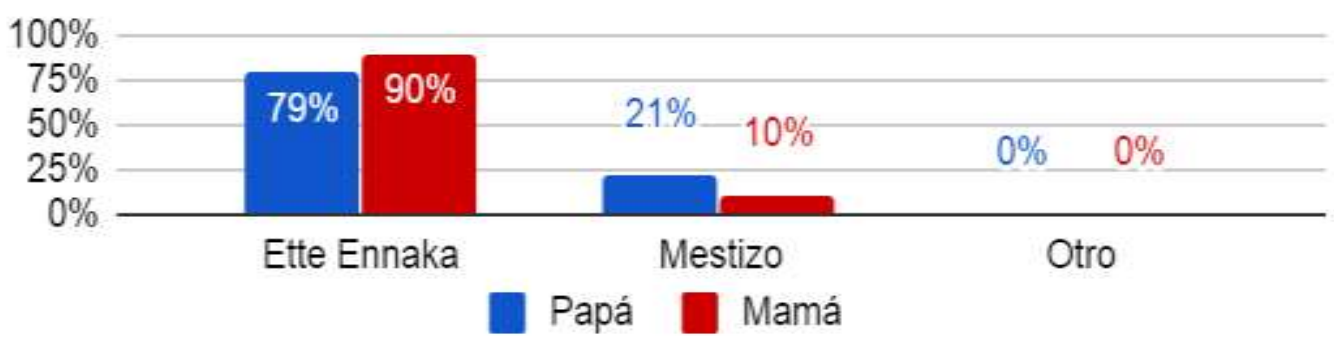

Gráfico 2. Actitudes de los niños ette taara frente a la identidad étnica de sus padres

\subsubsection{Actitudes hacia la lengua y su enseñanza}

El análisis de estas variables permitió determinar la aceptación de la investigación por parte de los estudiantes. Los niños y niñas objeto de estudio reconocen la existencia de una lengua propia en su comunidad. Consideran que su lengua es importante, ya que los identifica como indígenas y hace parte de su cultura.

Informante $\mathrm{N}^{\circ}$ 5: El etetala [ette taara] es de nosotros aquí

Informante $\mathrm{N}^{\circ} 11$ : el wacha no habla tetara [ette taara] aca si

Dentro del ámbito familiar, los datos dieron como resultado que dentro de cada hogar existen miembros que hablan la lengua, lo que constituye un recurso significativo para el proceso de enseñanza y revitalización del ette taara. (ver Gráfico 3). 


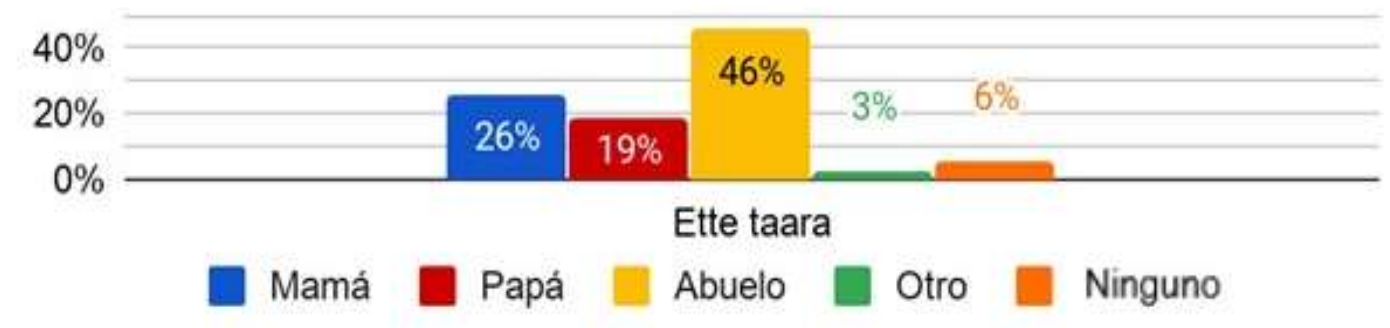

Gráfico 3. Relación porcentual de los hablantes ette taara según los miembros de las familias

Sin embargo, en el siguiente interrogante, se observa que los niños en su gran mayoría no hablan la lengua nativa, lo que demuestra una actitud lingüística negativa y desinteresada por parte del núcleo familiar (ver Gráfico 4).

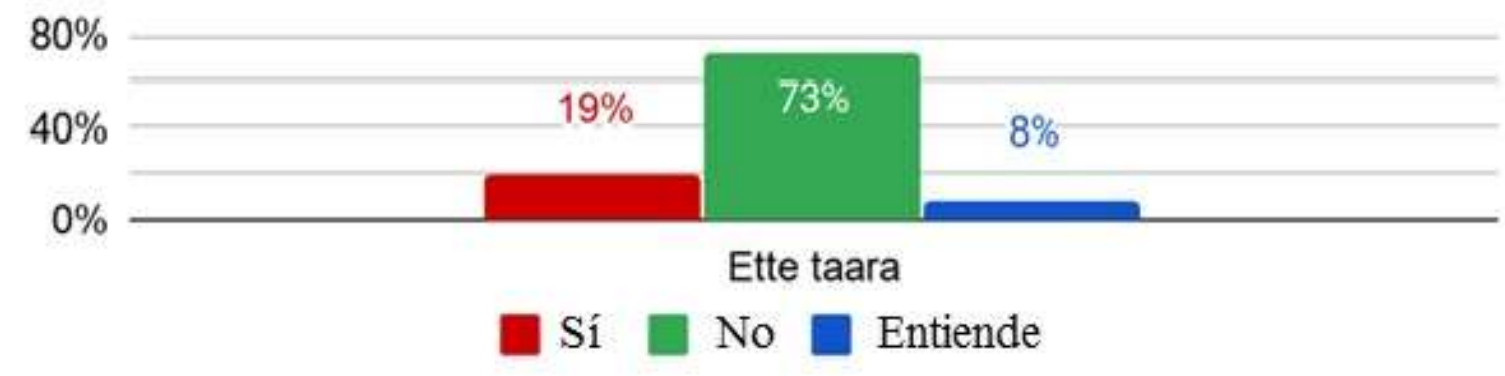

Gráfico 4. Relación porcentual de los niños que dominan la lengua ette taara

Según miembros de la comunidad, entre algunos de los factores que han causado el debilitamiento de la lengua se atribuye a los frecuentes matrimonios con personas no pertenecientes a la comunidad ette ennaka, la inconstancia en el uso de la lengua y la falta de decisión de los padres para enseñarla. A pesar de esta situación, los escolares tienen un alto grado de interés y afinidad hacia su lengua nativa, pues, aunque hablen el idioma español y presenten debilidad hablando su lengua vernácula, los niños y niñas del ciclo Moomate muestran una proximidad con el ette taara (ver Gráfico 5). 


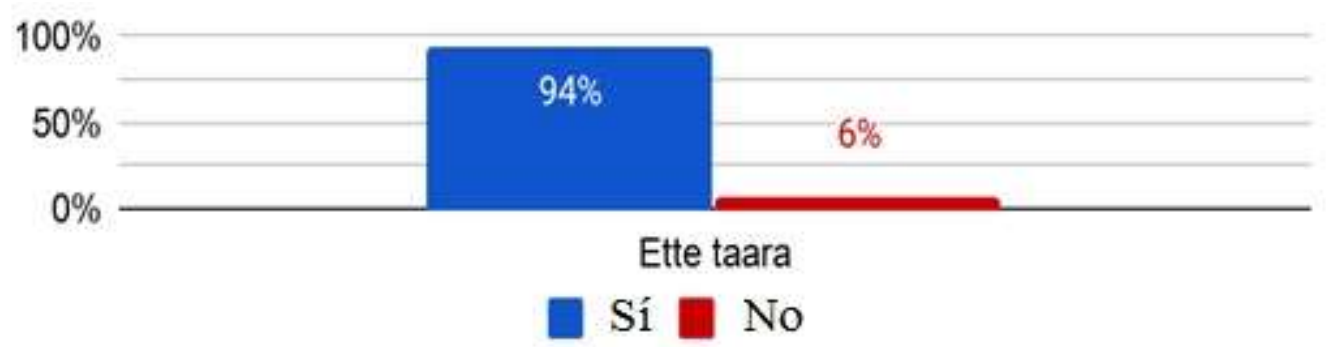

Gráfico 5. Relación porcentual del acercamiento de los niños del ciclo Moomate a la lengua ette taara

Con respecto a la actitud sobre la enseñanza del ette taara; diariamente los escolares, en compañía de los etnoeducadores, asisten a la casa tradicional, donde los gruta kawi (ancianos o sabedores) enseñan a los niños de la comunidad, a través de la oralidad, los saludos tradicionales, la denominación de objetos y partes del cuerpo, fabricación de objetos culturales, narración de historias y ceremonias o bailes tradicionales. En este sitio sagrado, se sugiere a todos los presentes el uso exclusivo del ette taara, como una estrategia de los enseñantes (gruta kawi) para enseñar y fortalecer la lengua materna a las nuevas generaciones (ver Gráfica 6):

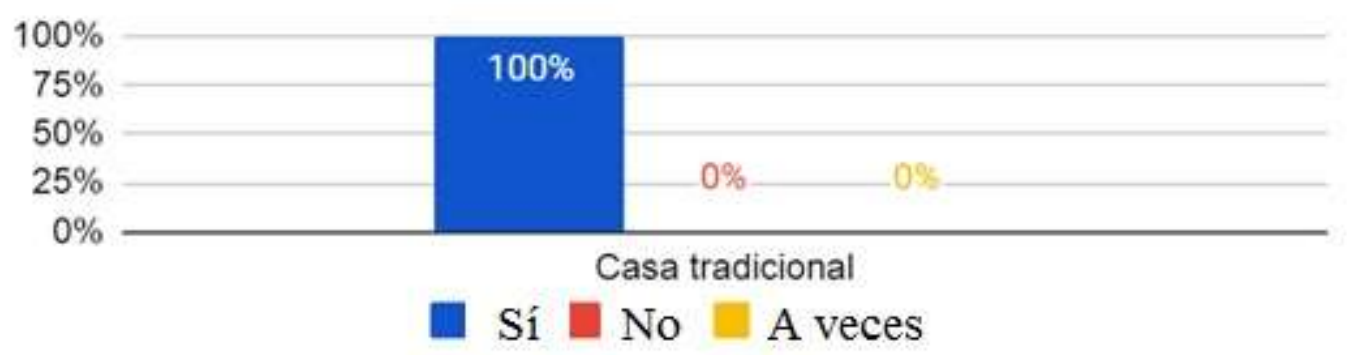

Gráfico 6. Relación porcentual del uso de la lengua ette taara en la casa tradicional

El hecho de asistir a la casa tradicional demuestra una actitud positiva por parte de los escolares por familiarizarse con la lengua ette taara y las tradiciones culturales de los ette ennaka. Asimismo, dentro de la institución, en clase de ette taara, los estudiantes muestran 
un alto grado de interés por aprender su lengua nativa y su cultura. (ver Gráfico 7). Sin embargo, en la institución se observa un desplazamiento lingüístico de la lengua nativa, pues esta solo se practica en clases de ette taara, lo que convierte esta situación en otro factor determinante de debilitamiento de su lengua vernácula (ver Gráfico 8).

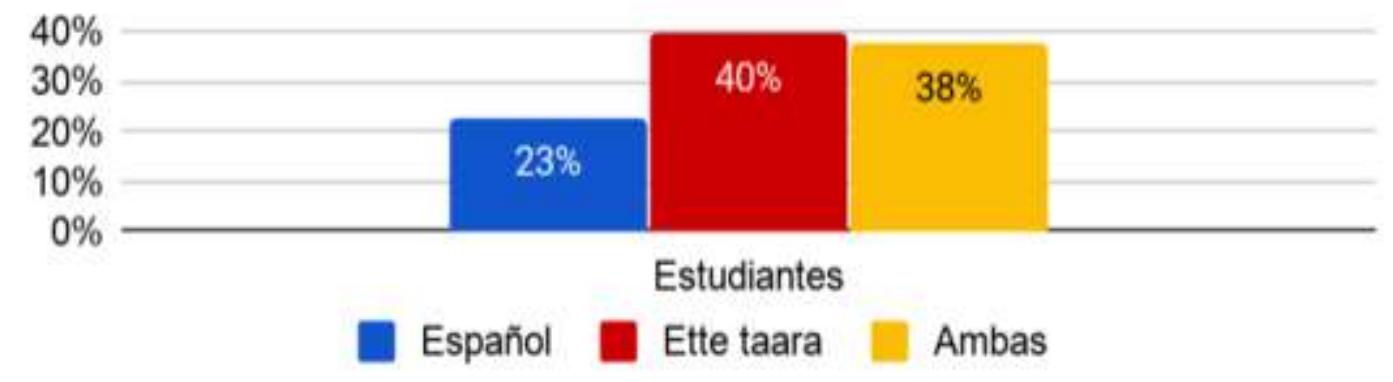

Gráfico 7. Relación porcentual de las preferencias de los niños por las clases de español y ette taara

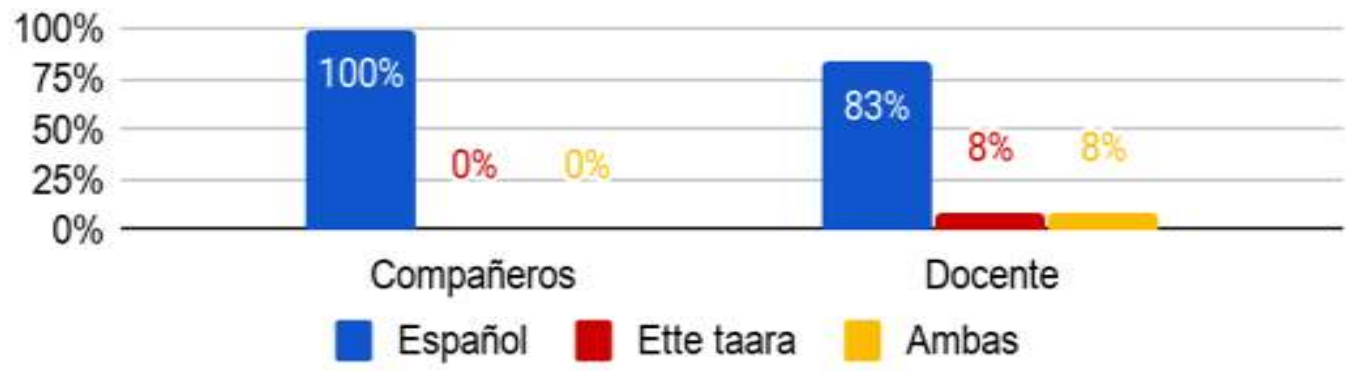

Gráfico 8. Relación porcentual del uso de la lengua ette taara en la institución por fuera de los horarios de clase

\subsubsection{Vitalidad lingüística}

Para el pueblo ette ennaka, según Trillos et al., (2014) el ette taara es el vehículo de comunicación con Yaao, y el no dominarla implica perder la posibilidad de acceder a los conocimientos primordiales de la cultura. En esta categoría, se buscaba identificar el grado de supervivencia del ette taara en la comunidad ette ennaka. Los datos arrojaron que existe 
un mayor uso del español, muy por encima del ette taara. (Gráficos 9 y 10), hecho vinculado al uso del español como primera lengua de comunicación.

Sin embargo, en el contexto familiar, los niños están utilizando el español, en espacios donde debería utilizarse el ette taara. Dato que evidencia, en primer lugar, la falta de compromiso y responsabilidad de los adultos en el proceso de apropiación lingüística y en segundo lugar, contribuyen al debilitamiento de la lengua al no transmitir el ette taara a las nuevas generaciones.

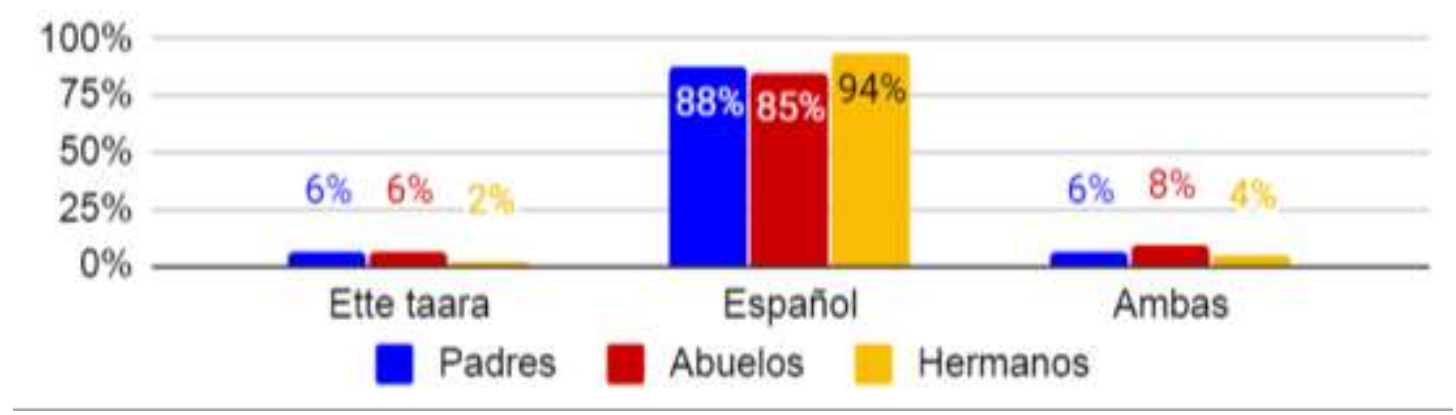

Gráfico 9. Relación porcentual del uso del español y del ette taara en los hogares

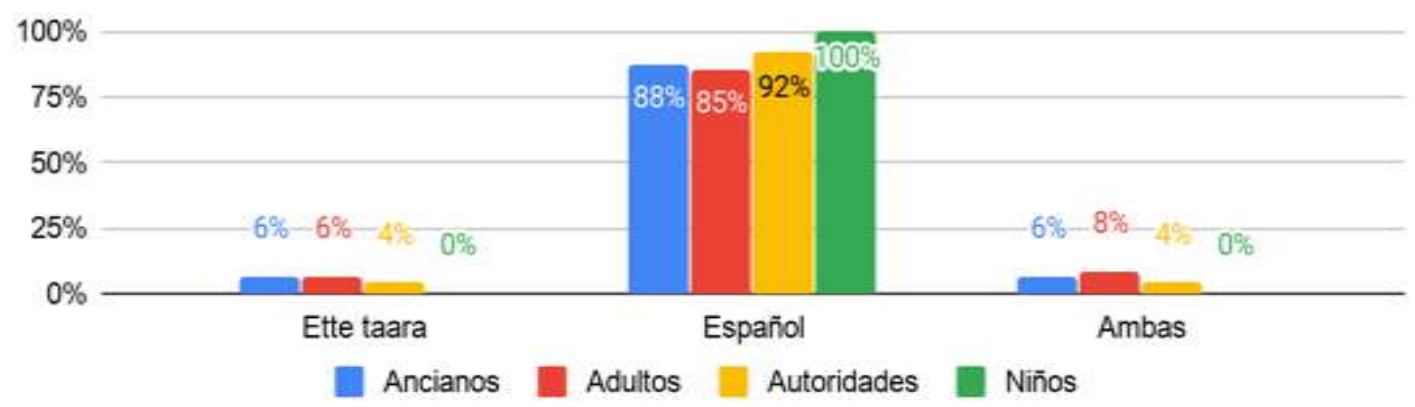

Gráfico 10. Relación porcentual del uso del español y del ette taara por los habitantes del pueblo

Dentro del ámbito social, al igual que en el contexto anterior, son escasos los espacios donde se parla el ette taara, al igual que las personas con que los niños puedan hablar y practicar la lengua materna (ver Gráfico 10). Sólo un número reducido de niños afirma hablar ette taara con ancianos y adultos de la comunidad; asimismo, aseguran hacer uso de 
las dos lenguas, pero lo que realmente se evidencia es que el español sigue siendo el idioma dominante.

Para finalizar, a nivel tecnológico se realizaron tres interrogantes (Gráficos 11, 12 y 13), con el fin de determinar el grado de contacto y familiarización que los escolares del ciclo Moomate tiene frente a las TIC, los cuales permitieron llevar a cabo el desarrollo de la propuesta de investigación.

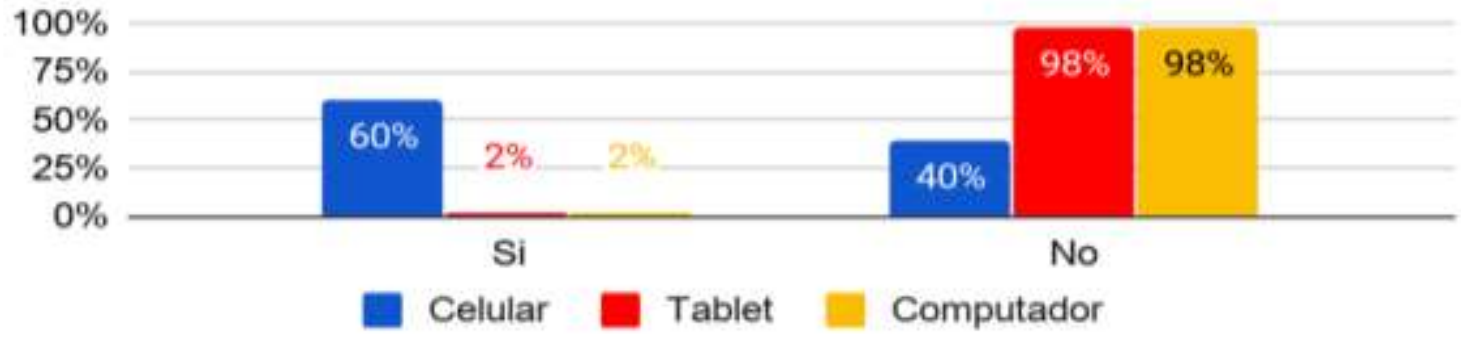

Gráfico 11. Relación porcentual de la posesión de dispositivos tecnológicos por los niños del ciclo Moomate

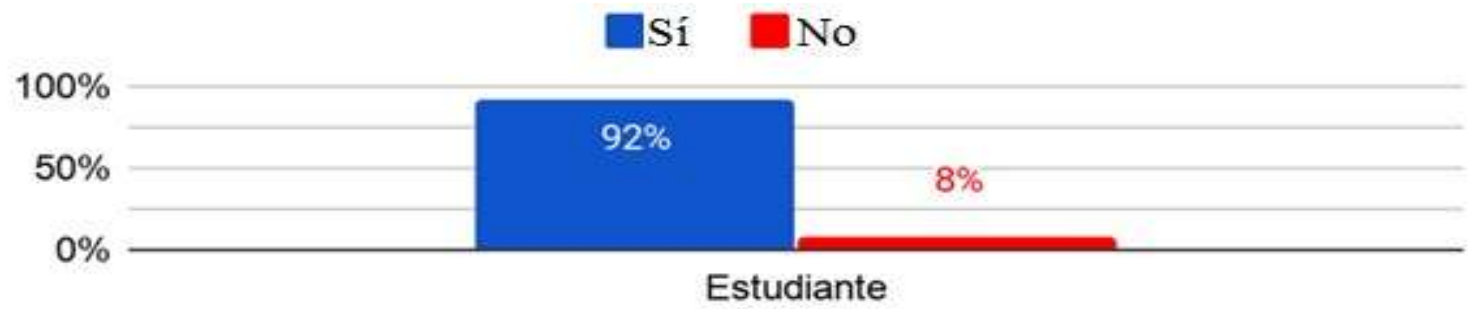

Gráfico 12. Relación porcentual de la inclinación de los niños del ciclo Moomate hacia el uso de dispositivos tecnológicos

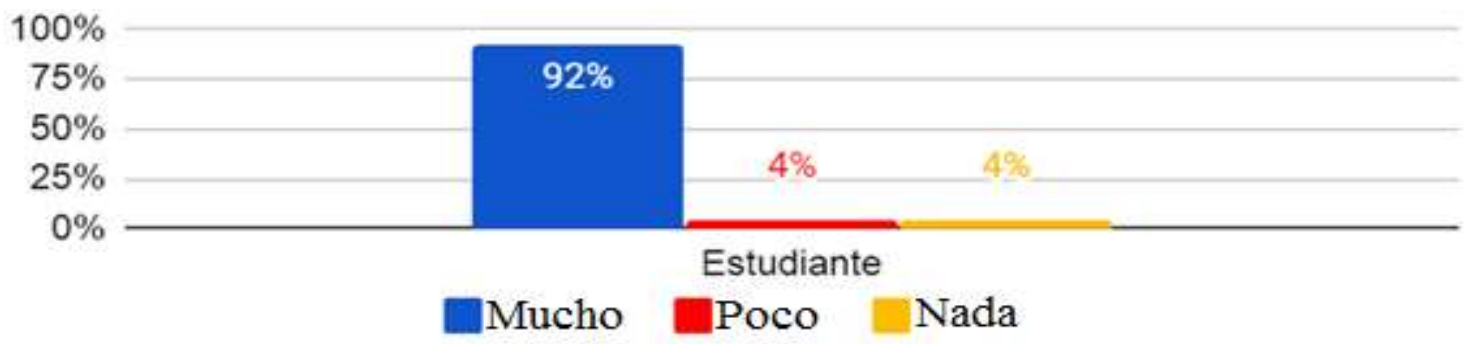

Gráfico 13. Relación porcentual de la inclinación de los niños del ciclo Moomate hacia el aprendizaje del ette taara por medio de los dispositivos tecnológicos 
Como bien se observa en las gráficas, los niños y niñas del ciclo moomate de la IEDEE muestran disposición para implementar las tecnologías dentro del aula de clases, pues se espera que sirva como herramienta didáctica para el fortalecimiento y preservación de la lengua y la cultura.

\subsection{Corpus léxico}

En base a los procesos dialógicos realizados con los etnoeducadores, se recolectó un corpus del léxico ette taara en el ciclo Moomate. En este proceso se definieron principalmente los campos semánticos más significativos, entre los cuales se encuentran los siguientes: animales, números, familia, frutas, cultura, fenómenos naturales, partes del cuerpo, colores y nociones con figuras.

\begin{tabular}{|c|c|c|c|}
\hline \multicolumn{4}{|c|}{ ANIMALES } \\
\hline ette taara & español & ette taara & Español \\
\hline Brega' & Hormiga & Buttu & Culebra \\
\hline Peekru & Perro & Kiitikkwi & Pájaro \\
\hline Biyansu’ & Gato & Kro'chu & Venado \\
\hline Aara' & Loro & sagwa' & Tortuga \\
\hline Kawaya & Caballo & Bitto & Cerdo \\
\hline kiiro’' & Gallina & Joo & Mico \\
\hline Kaj bri & Ratón & Kwita' & Ardilla \\
\hline Kiirottu & Pollito & Patu & Pato \\
\hline Waa & Pescado & Tiu & Conejo \\
\hline ma'ma & Sapo & & \\
\hline \multicolumn{4}{|c|}{ FRUTAS } \\
\hline Dukkwruwa' & Guanábana & Fresa & Fresa \\
\hline Beelug & Melón & Coco & Coco \\
\hline Paarada & Guineo & Dookowakraa & Tamarindo \\
\hline Pattiyu & Patilla & Tiukra’ & Mamón \\
\hline Piinsiriwa' & Maracuyá & Maagu & Mango \\
\hline \multicolumn{4}{|c|}{ FAMILIA } \\
\hline Na taata & Mi mamá & Mogwita & Nieto-nieta \\
\hline Lukka' & Tío paterno & Na yaau & Mi papá \\
\hline Kwika & Tío Materno & Wata' & Tía paterna \\
\hline Yee antari' & Primo & Wata' & Tía materna \\
\hline
\end{tabular}

LINGÜÍSTICA Y LITERATURA 


\begin{tabular}{|c|c|c|c|}
\hline Yuunari' & Abuela & Yee & Hermano \\
\hline Peenari & Abuelo & Yee & Hermana \\
\hline Oggwe & Hija-Hijo & & \\
\hline \multicolumn{4}{|c|}{ FIGURAS Y NOCIONES } \\
\hline Brabrabrada & Redondo & Ka’ya & Angosto \\
\hline ka’ye ka’ye & Cuadrado & Jeenare' & Triángulo \\
\hline Diisu ka'ye & Rectangular & Ka'ye’ & Ancho \\
\hline Briigari & Cilindro & Sootiiri & Cono \\
\hline Diisu yuuta & Corto & & \\
\hline \multicolumn{4}{|c|}{ NÚMEROS } \\
\hline Tiite’ & 1-uno & Jatta kutte & 6- seis \\
\hline Tiimujna' - bujna' & 2-dos & Tiimujna’ & 7-siete \\
\hline Tiimajna' Maajna' & 3 -tres & $\begin{array}{l}\text { Kisamaajna' } \\
\text { brii'yee'e' }\end{array}$ & 8- ocho \\
\hline Brii' yee'e' & 4-cuatro & $\begin{array}{l}\text { Kisamujna brii' } \\
\text { yee'e' yeemekenta }\end{array}$ & 9-nueve \\
\hline Yeemekenta & 5-cinco & Jatta mujna' & 10-diez \\
\hline \multicolumn{4}{|c|}{ PARTES DEL CUERPO } \\
\hline Kwa & Lengua & Kreela & Tobillo \\
\hline Kakkwasa & Boca & Sessero’ & Uña \\
\hline Gangrwa ukkwbrila & Hombro & Gangrwa & Brazo \\
\hline Dij & Diente & Kree' & Codo \\
\hline La'kkrala & Espalda & Jattakra & Mano \\
\hline Osokwala & Mejilla & Dukkwa & Pierna \\
\hline Kassa & Pies & Kree' & Rodilla \\
\hline $\mathrm{Aj}$ & Cabello & Wokwala & Dedo \\
\hline Kussaka & Oreja & Daj & Nariz \\
\hline \multirow[t]{2}{*}{ Jaakrala } & Cabeza & Waakwa & Ojo \\
\hline & & Yu'me sula & Barriga \\
\hline \multicolumn{4}{|c|}{ FENÓMENOS NATURALES } \\
\hline Diitake & Agua & Monse' & Nube \\
\hline Diiyo’ & Lluvia & Yu'wa itta & Cielo Nublado \\
\hline Itta’ & Cielo & Digga & Sol \\
\hline Ittila’ & Tierra & Wiiyento & Brisa \\
\hline Maamasu' & Luna & & \\
\hline \multicolumn{4}{|c|}{ CULTURA } \\
\hline $\begin{array}{l}\text { Grutaka'kwi } \\
\text { jataka'wa }\end{array}$ & $\begin{array}{l}\text { Casa } \\
\text { tradicional }\end{array}$ & Wisawi & Manantial \\
\hline Yajgowi & $\begin{array}{l}\text { Mochila de } \\
\text { carga }\end{array}$ & Koggo & Arroyo \\
\hline Bi’la & Arco & Tuuntiry & Flauta \\
\hline Rokkra & Flecha & Too & Maraca \\
\hline Kantwasa & Montañas & & \\
\hline
\end{tabular}




\begin{tabular}{|l|l|l|l|}
\hline \multicolumn{4}{|c|}{ COLORES } \\
\hline Wingda tuu' & Amarillo & Itti itti tuu' & Marrón \\
\hline Sij & Azul & Sommo tuu' & Blanco \\
\hline Kroo tuu' & Rojo & Sij tuni & Negro \\
\hline Sajgada tuu' & Verde & Krokrokrokroda tuu & Morado \\
\hline Wingrada tuu' & Naranjado & kane kane tuu' & Gris \\
\hline
\end{tabular}

Tabla 2. Corpus léxico en uso de los niños del ciclo Moomate de la IEDEE

\section{Propuesta}

\subsection{Diseño de una herramienta didáctica para el fortalecimiento del léxico mediante el uso de las TIC}

Con el objetivo de fortalecer el léxico se desarrolló una aplicación móvil basada en GODOT $^{8}$. Este lenguaje de programación permite diseñar juegos dinámicos e interactivos. Al respecto, Gómez, García y Cordón (2015) consideraron que un aplicativo móvil permite desarrollar habilidades cognitivas y de comunicación en los más pequeños de una forma lúdica.

Para tal efecto, se diseñó la aplicación ette taara, que se compone de gráficos y juegos adaptados a sus propias necesidades. Se caracteriza por contar con nueve campos semánticos, donde se incluyen las estrategias más exitosas ideadas por los etnoeducadores. Además, la herramienta didáctica se complementa con una cartilla que desarrolla actividades de asociación, escritura básica, dibujo, motricidad fina, coloreo, conteo, entre otras.

Así, el propósito de la aplicación es convertirse en un material didáctico que fortalezca la apropiación del léxico, y asimismo, sea un insumo para el estudio de la lengua en la escuela y el núcleo familiar. Frente a esta, es importante manifestar que el pueblo ette ennaka busca que los niños estimulen las competencias digitales, es decir, el escenario de aprendizaje de la aplicación ette taara se convierte en un punto integrador entre el material didáctico y la

8. GODOT: Motor de videojuegos multiplataforma para crear juegos 2D y 3D, el cual provee un conjunto de herramientas comunes para que los usuarios puedan enfocarse en crear juegos que pueden exportarse en un sólo clic a numerosas plataformas, incluyendo las principales plataformas de escritorio (Linux, macOS, Windows), móviles (Android, iOS) y basadas en la web (HTML5). 
experiencia de aprendizaje. De este modo, los estudiantes se apropian del léxico en un escenario interactivo.

\subsubsection{Descripción de la aplicación móvil}

La aplicación ette taara fue desarrollada y diseñada por un equipo interdisciplinario compuesto por docentes etnoeducadores, docentes en lingüística, ingenieros de sistemas, programadores y un grupo de diseñadores gráficos. La aplicación cuenta con 110 frases y 110 lexemas, tanto en ette taara como en español. Asimismo, cuenta con 120 ilustraciones y 3 sonidos de fondo, con el fin de ambientar mejor el escenario de aprendizaje para el niño.

Para esta aplicación, se recogió un corpus del léxico ette taara en uso de los niños del ciclo Moomate. Para este proceso, se visitó el resguardo de Issa Oristuna. Con el apoyo de los etnoeducadores, se recogió un total de 110 léxicos ette taara divididos en campos semánticos (animales, números, familia, frutas, cultura, fenómenos naturales, partes del cuerpo, colores y nociones con figuras). Asimismo, se contó con la colaboración del cabildo, de los líderes comunitarios y los ancianos del pueblo ette ennaka para la realización de diálogos sobre las correcciones y confirmaciones necesarias de las muestras léxicas recogidas.

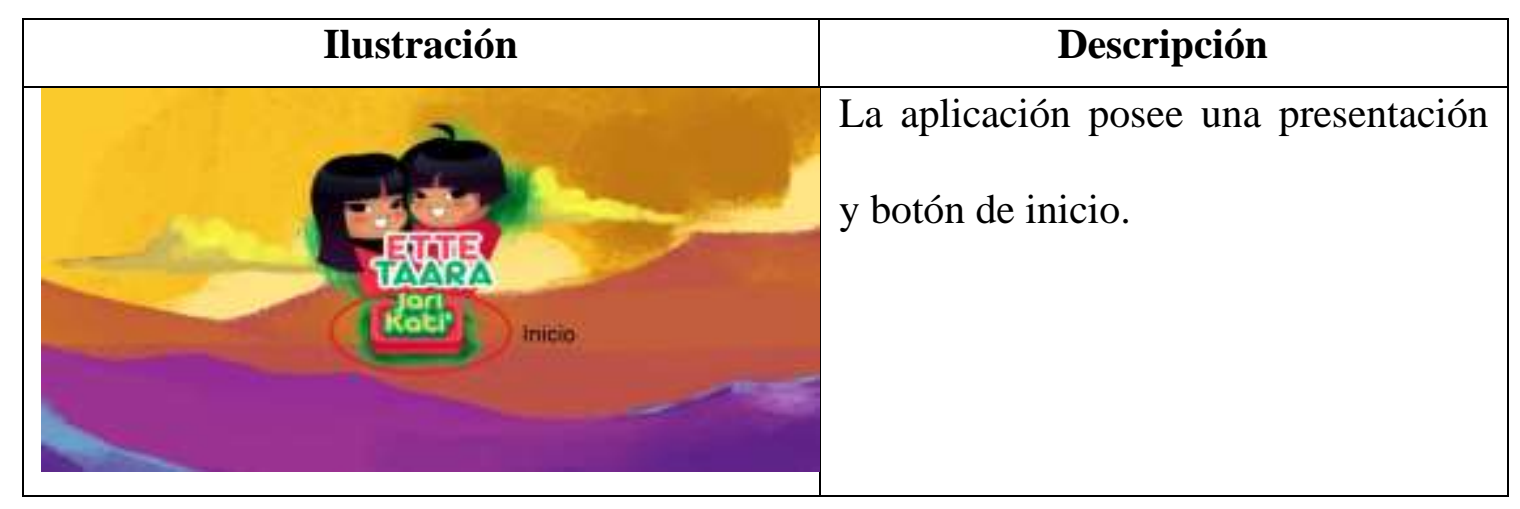




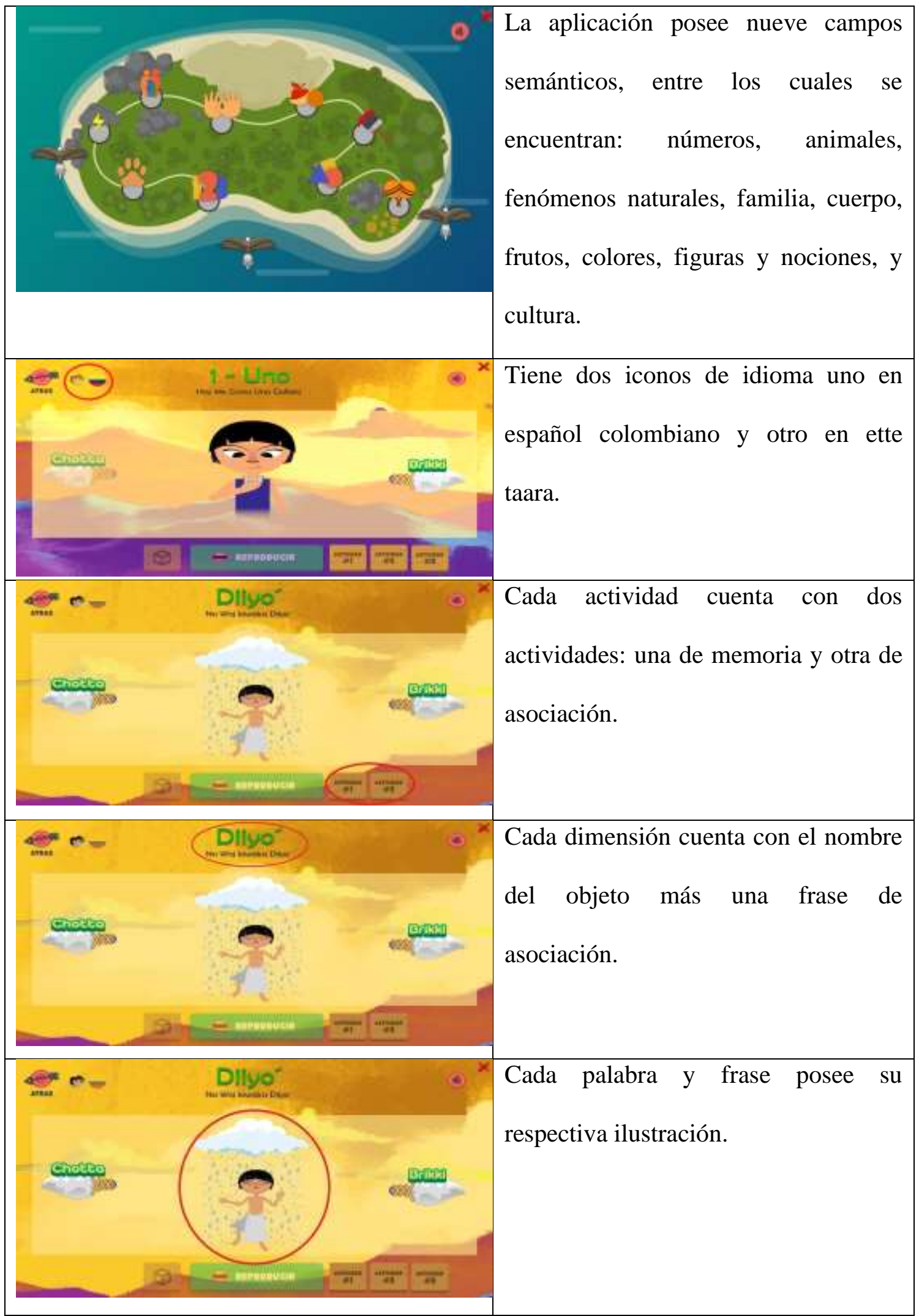




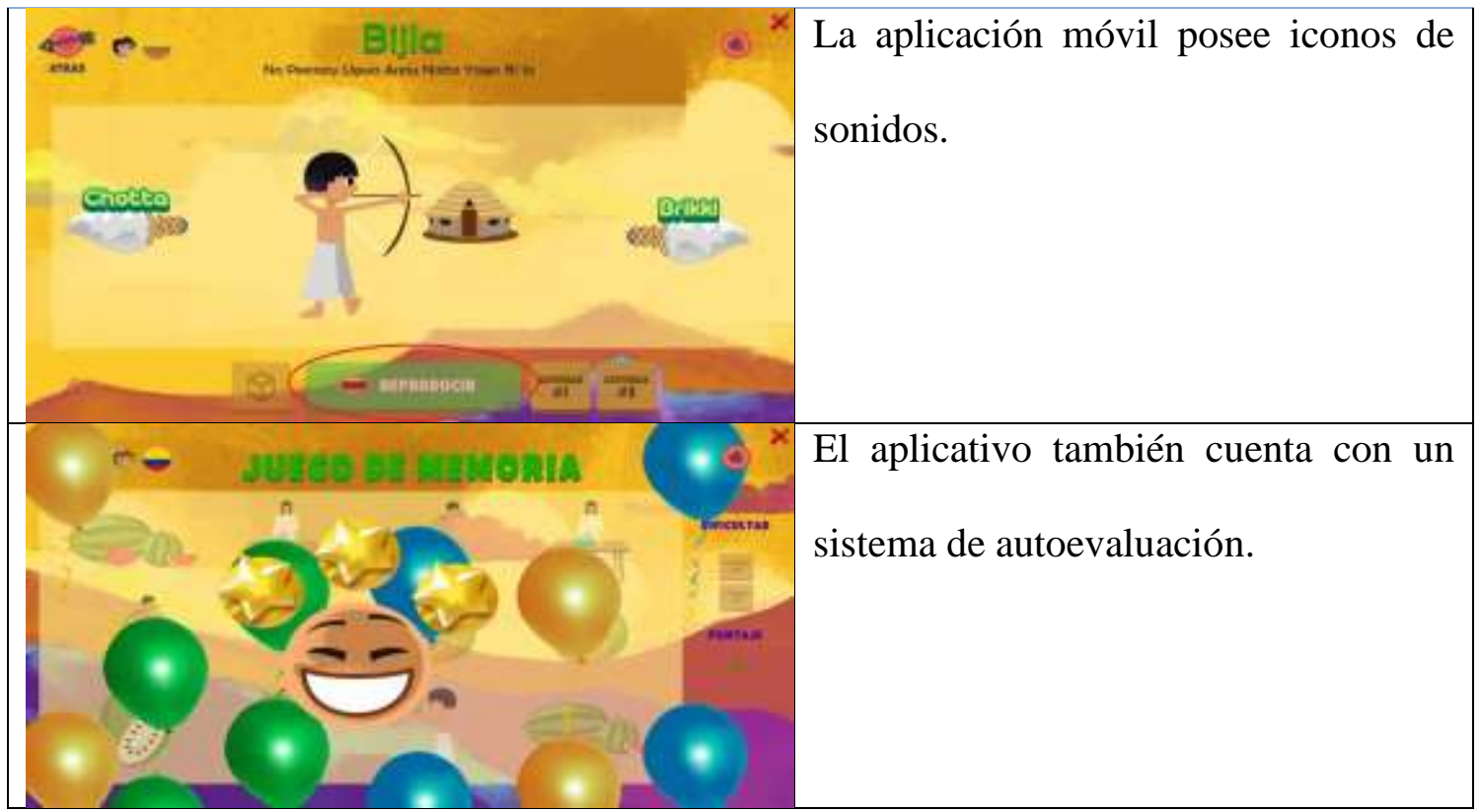

Tabla 3. Descripción del aplicativo móvil ette taara

\subsubsection{Descripción de la cartilla Juri Nagkre wi’la ette taara}

La Cartilla Juri Nagkre wi'la ette taara (en español, aprendamos ette taara) es un recurso didáctico que complementa el recorrido por la aplicación móvil, la cual cuenta con los siguientes temas: vocales, alfabeto, números, colores, figuras, familia, cuerpo, frutas, animales, medios de transporte, fenómenos naturales y cultura. Asimismo, la cartilla está complementada con actividades de asociación, identificación, coloreo, aprestamiento, motricidad y escritura. Se compone de 72 páginas de actividades para los niños, con el propósito de fortalecer la apropiación del léxico.

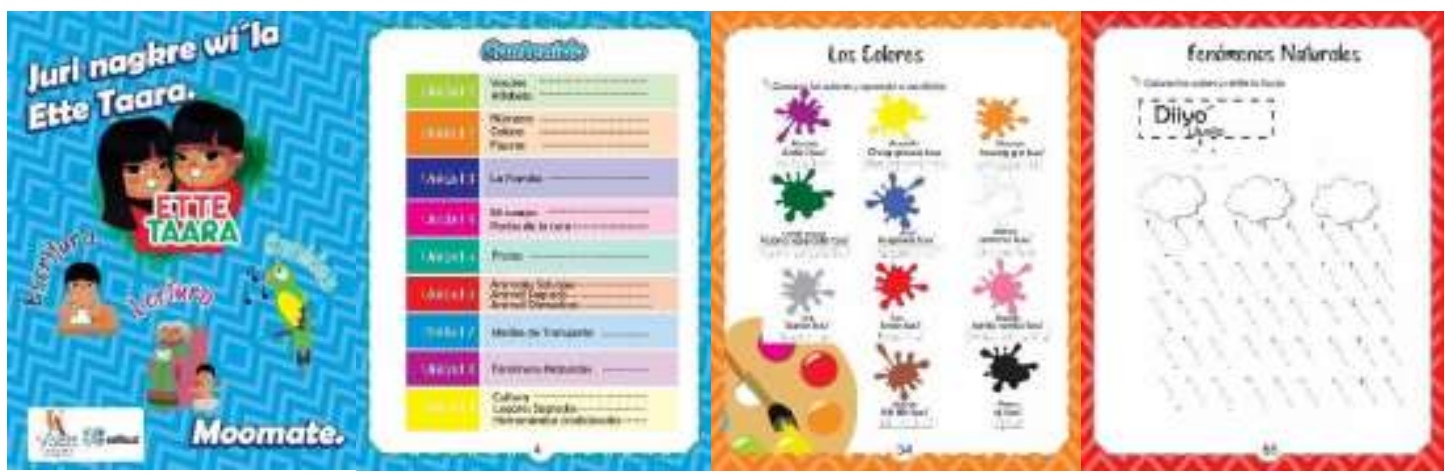




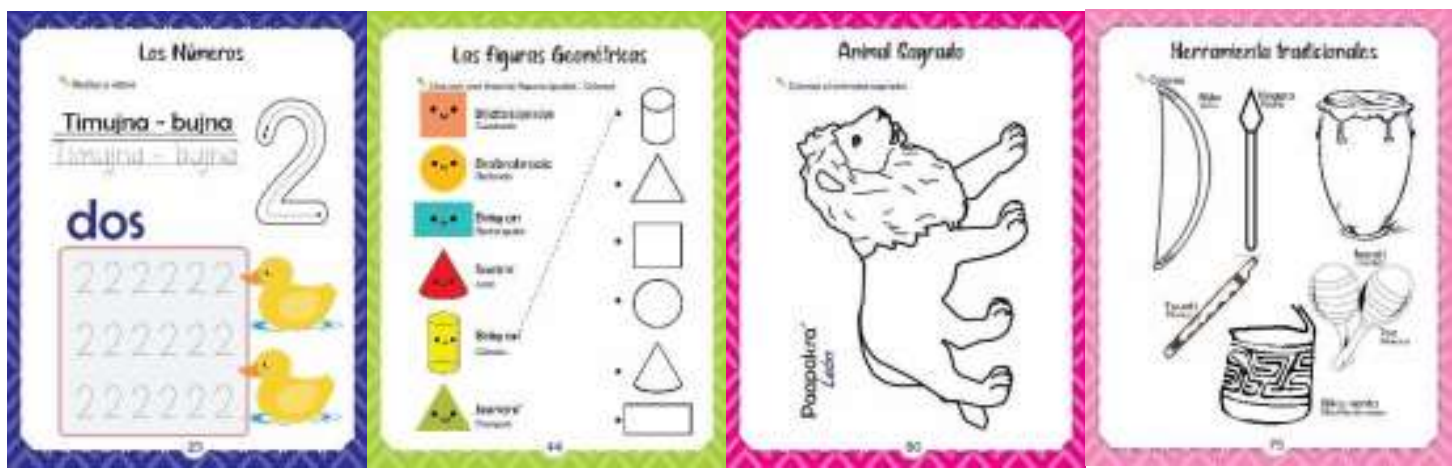

Gráfico 14. Muestra de algunas páginas de la cartilla Juri Nagkre wi ’la ette taara

\section{Conclusiones}

Después de un análisis de los resultados de la investigación, y teniendo en cuenta todos los factores sociales, lingüísticos y educativos que intervinieron en ella, se llegó a las siguientes conclusiones:

a) Las estrategias didácticas más significativas utilizadas por los etnoeducadores son: el juego, el trabajo con materiales del entorno disponibles (piedritas, arena, hojas de los árboles, etc.), asociación entre imagen y palabra, enseñanza por campos semánticos, cantos, rondas y bailes tradicionales.

b) En cuanto a las experiencias exitosas que dieron resultados en los procesos de enseñanza y aprendizaje de la apropiación del léxico ette taara, sobresalió el uso de elementos sagrados, aprendizaje por asociación, observación del medio y la naturaleza, demostraciones de bailes tradicionales del pueblo ette ennaka en compañía de mayores o sabedoras y el uso de materiales del entorno.

c) A nivel lingüístico, el ette taara es una lengua que aún sigue en estado de severo peligro de extinción. A pesar de la constante realización de acciones tendientes para su rehabilitación, los mismos miembros de la comunidad contribuyen a su deterioro, pues, siendo la lengua de la tradición oral, esta ha dejado de ser transmitida a las nuevas generaciones, desplazando no sólo la lengua nativa, sino también a su cultura y sus tradiciones ancestrales. 


\section{Referencias bibliográficas}

1. Acosta, V. \& Moreno, A. (1999). Dificultades del lenguaje en ambientes educativos. Barcelona: Masson.

2. Allen, V. F. (1983). Techniques in Teaching Vocabulary. Oxford: Oxford University Press.

3. Ayala Estrada, W. A. (2018). Léxico adquirido en Colombia. Lingüística y Literatura, (73), 115-135. Recuperado de https://revistas.udea.edu.co/index.php/lyl/article/view/331136

4. Bavaresco, A. (2013). Proceso metodológico en la investigación. Cómo hacer un diseño de investigación ( $6^{\text {a }}$ edición). Maracaibo: Imprenta internacional, CA.

5. Beltrán J. \& Mansilla, J. (2013). Coherencia entre las estrategias didácticas y las creencias curriculares de los docentes de segundo ciclo, a partir de las actividades didácticas. Perfiles educativos, $\quad$ 139(35) 25-39. Recuperado de http://www.scielo.org.mx/scielo.php?script=sci_arttext\&pid=S018526982013000100003\&l $\mathrm{ng}=\mathrm{es} \& \mathrm{t} \operatorname{lng}=\mathrm{es}$

6. Bolinder, G. (1987). Los últimos indios chimila. Museo del Oro. Boletín N ${ }^{\circ}$ 8. Bogotá: Banco de la República. 34-56.

7. Bruner, J. (1984). Acción, pensamiento y lenguaje. Madrid: Alianza Editorial.

8. Cárdenas, I., Gómez, M. \& Abrego, R. (2013). Tecnologías educativas y estrategias didácticas: criterios de selección. Revista Educación y Tecnología, (3), 190-206. Recuperado de

https://www.researchgate.net/profile/Marcela_Gomez_Zermeno/publication/266385186_Tec nologias_educativas_y_estrategias_didacticas_criterios_de_seleccion/links/542ec1680cf277 d58e8eeb21/Tecnologias-educativas-y-estrategias-didacticas-criterios-de-seleccion.pdf 9. Carrasco, E. (2015). Nivel de vocabulario receptivo en niños de 4 y 5 años de centros educativos estatales y privados del distrito de Surquillo (Tesis de maestría) Lima, Perú. Pontificia Universidad Católica del Perú. 
10. Constenla, A. (1993). La familia chibcha. En M. L. Rodríguez de Montes (Ed.), Estado actual de la clasificación de las lenguas indígenas de Colombia, (pp. 75-125). Bogotá: Instituto Caro y Cuervo.

11. Creswell, W. \& Plano Clark, V. (2011) Diseño y realización de investigaciones de métodos mixtos ( $2^{\mathrm{a}}$ edición). Los Ángeles: Sage Publications.

12. Guerrero, A. (2009). Los materiales didácticos en el aula. Temas para la Educación, 5, 1-7. Recuperado de https://www.feandalucia.ccoo.es/docu/p5sd6415.pdf

13. Gómez, R.; García, A \& Cordón, J. (2015). Aprender a leer y escribir: aplicaciones para el aprendizaje de la lectoescritura. Education in the Knowledge Society, 16(4), 118-137. Universidad de Salamanca. Salamanca, España.

14. Hernández Sampieri, R., Fernández Collado, C. \& Baptista Lucio, P. (2010). Metodología de la Investigación. ( $5^{\text {a }}$ edición). Recuperado de https://www.esup.edu.pe/descargas/dep_investigacion/Metodologia\%20de\%20la\%20investi gaci\%C3\%B3n\%205ta\%20Edici\%C3\%B3n.pdf

15. Higueras, M. (2009). Aprender y enseñar léxico. Didáctica del español como lengua extranjera. Monográficos marcoELE, 9, 111-126. España: Expolingua.

16. López, E., Cacheiro, M., Camilli, C. \& Fuentes, J. (2016). Didáctica general y formación del profesorado. España: Universidad de la Rioja.

17. Loukotka, C. (1968). Classification of South American Indian Languages (Vol. 7). Los Angeles: Reference Series.

18. Martínez, J. (2011). Metodologías de la investigación cualitativa. Silogismo más que conceptos, 8(1), 27-38.

19. Medina, A. (2005). De la experiencia profesional a la sabiduría didáctica. Enseñanza: Anuario Interuniversitario de Didáctica, 23, 269-285

20. Meza Cascante, L. G. (2015). El paradigma positivista y la concepción dialéctica del conocimiento. Revista Digital: Matemática, Educación E Internet, 4(2). https://doi.org/10.18845/rdmei.v4i2.2296

21. Ministerio de Cultura de Colombia. (2010). Informe Preliminar sobre la Primera Campaña del Autodiagnóstico Sociolingüístico del Programa de Protección a la Diversidad Etnolingüística -PPDE (versión provisional). Programa de Protección a la Diversidad 
Etnolingüística (PPDE). Bogotá: Ministerio de Cultura de Colombia. Recuperado de https://www.mincultura.gov.co/SiteAssets/documentos/Despacho/Lenguas/informe_prelimi nar_autodiagnostico_sociolinguistico.pdf

22. Murillo, J \& Martínez C. (2010). Investigación etnográfica. Métodos de investigación educativa en educación especial. México: Universidad Autónoma Metropolitana.

23. Niño, J.C. (2016) La anatomía de la casa. Humanización y ciclo vital de la vivienda ette (Chimila). Universidad de los Andes. Bogotá. Recuperado de https://www.redalyc.org/jatsRepo/3416/341651104006/html/index.html\#fn3

24. Niño. J.C. (2018). Diccionario de la lengua ette. Bogotá: Colección Ágora.

25. Ogden, C. \& Richards, L. (1954). El significado del significado. Buenos Aires: Paidós.

26. Otzen, T. \& Manterola C. (2017) Técnicas de muestreo sobre una población a estudio. International Journal of Morphology, 35(1):227-232.

27. Picado, F. (2006). Didáctica general. Una perspectiva integradora. ( $1^{\mathrm{a}}$ edición). San José: Editorial Universidad Estatal a Distancia.

28. Pueblo indígena Ette Ennaka y Cabildo Indígena Ette Ennaka (2012) Plan de vida Ette Ennaka. Issa Oristunna: Fondo DRI, Red de Solidaridad Social, Asuntos Indígenas y ReCC. 29. Pueblo indígena Ette Ennaka. (2015) Proyecto etnoeducativo. Nata Nagkre Ori Weeke'e Ennara Butteriya Papellu Riigowala. Bogotá: Ministerio de Educación Nacional.

30. Pueblo indígena Ette Ennaka. (2012) Plan de salvaguarda. Diagnóstico y líneas de acción para las comunidades wiwa de la Sierra Nevada De Santa Marta (Departamentos Cesar, Magdalena y Guajira) en el marco del cumplimiento del Auto 004 de 2009. Bogotá: Ministerio del Interior. Recuperado de https://siic.mininterior.gov.co/sites/default/files/pueblo_wiwa__diagnostico_comunitario_0.pdf

31. Reichel-Dolmatoff, G. (1946). Etnografía chimila. Boletín de Arqueología, vol. 2., 95192. Bogotá: Instituto Colombiano de Antropología e Historia.

32. Ríos, A. (2019) Ubicación de resguardos y asentamientos de la Comunidad Ette Ennaka en la actualidad. Bogotá: Cartógrafo.

33. Roux, R. \& Anzures, R. (2015). Estrategias de aprendizaje y su relación con el rendimiento académico en estudiantes de una escuela privada de educación media superior. 
Revista Electrónica Actualidades Investigativas en Educación, 15(1) 1-16. Recuperado de https://www.redalyc.org/pdf/447/44733027014.pdf

35. Tébar Belmonte, L. \& Quiñonez Cárdenas, J. (2003): El perfil del profesor mediador. Aula XXI, Santillana, Madrid. [Versión electrónica]. Teoría de la educación: educación y cultura en la sociedad de la información, 4. Recuperado de https://gredos.usal.es/handle/10366/56463

35. Trillos M. (1996) Categorías gramaticales del ette taara: lengua de los chimila. Lenguas aborígenes de Colombia. Bogotá. Colciencias/Universidad de los Andes/CCELA.

36. Trillos, M. et al., (2014). Modelo didáctico: Enseñanza del español L2. Colciencias/ Universidad del Atlántico/Consejo de Mayores del Pueblo Ette Ennaka. Barranquilla, (en edición).

37. Trillos, M. (1993). Estudio morfológico del chimila. (Beca de investigación de Colcultura). Bogotá: Ministerio de Cultura.

38. Uribe, C. (1987). Chimila. Introducción a la Colombia amerindia (pp. 51-62). Bogotá: Instituto Colombiano de Antropología e Historia. 